\title{
Screening the dermatological potential of Plectranthus species components: antioxidant and inhibitory capacities over elastase, collagenase and tyrosinase
}

\author{
Joana M. Andrade ${ }^{a}$ (D) Eva María Domínguez-Martín ${ }^{\mathrm{a}, \mathrm{b}}$ (D), Marisa Nicolai ${ }^{\mathrm{a}}$ (D), Célia Faustino ${ }^{c}$ (D), \\ Luís Monteiro Rodrigues ${ }^{\mathrm{a}}$ (D) and Patrícia Rijo ${ }^{\mathrm{a}, \mathrm{c}}$ (D) \\ ${ }^{a}$ Research Center for Biosciences and Health Technologies (CBIOS), Universidade Lusófona de Humanidades e Tecnologias, Lisboa, Portugal; \\ bepartment of Biomedical Sciences, Faculty of Pharmacy, University of Alcalá, Madrid, Spain; 'Research Institute for Medicines (iMed.ULisboa), \\ Faculty of Pharmacy, University of Lisbon (ULisboa), Lisbon, Portugal
}

\section{ABSTRACT}

A series of Plectranthus spp. plant extracts (aqueous, acetonic, methanolic and ethyl acetic) obtained from eight different species, and previously isolated compounds (ranging from polyphenols, diterpenes and triterpenes), were assayed for in vitro inhibition of the skin-related enzymes tyrosinase, collagenase and elastase, and for studying their antioxidant properties. The ethyl acetic extracts of $P$. grandidentatus and $P$. ecklonii registered the highest antioxidant activity, whereas acetonic, methanolic and ethyl acetic extracts of $P$. ecklonii, $P$. grandidentatus, $P$. madagascariensis and $P$. saccatus concerning the enzymatic inhibition assays revealed high anti-tyrosinase and anti-collagenase activities. From the isolated compounds tested, abietane diterpenes and triterpenes were highly active against tyrosinase and elastase activity. Overall, the experimental results showed the powerful antioxidant and inhibitory action on skin-related enzymes tyrosinase, collagenase and elastase of Plectranthus spp. extracts and/or isolated compounds, supporting their further research as bioactive metabolites against skin sagging and hyperpigmentation in cosmetic and pharmaceutical formulations.

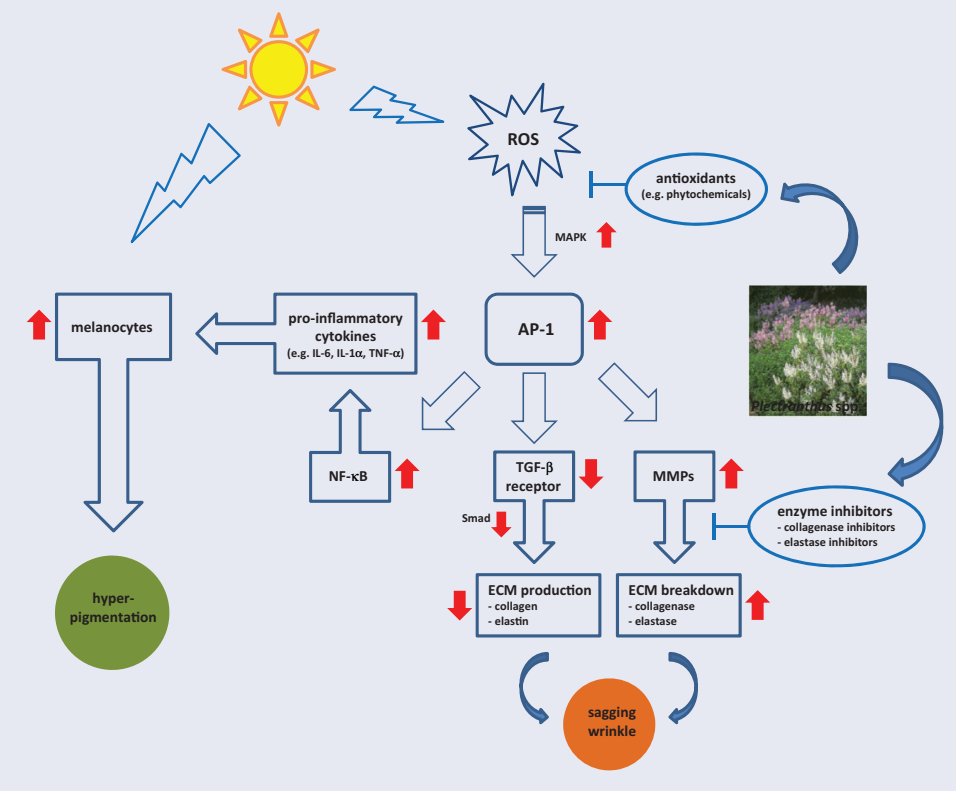

\section{Introduction}

Skin care is a growing concern for the consumer, who is increasingly aware of its maintenance for the preservation of favourable aesthetic appearance, and on its direct impact on the prevention of many skin disorders ${ }^{1}$. In the last years, more attention has been devoted to skin as a mirror for general health condition. Dermatological "links" have been reported to the main
ARTICLE HISTORY

Received 31 August 2020

Revised 30 November 2020

Accepted 1 December 2020

\section{KEYWORDS}

Plectranthus; antioxidant;

tyrosinase; collage-

nase; elastase 
The origin of many of these skin disorders has been linked to oxidative stress ${ }^{13,14}$, which is commonly promoted by chemicals, microorganisms and ultraviolet (UV) solar radiation ${ }^{15-17}$. Exposure to UV radiation can be particularly adverse for people with low melanin production, such as Caucasians, due to the fact of generating reactive oxygen species (ROS), such as superoxide anions, hydrogen peroxide $\left(\mathrm{H}_{2} \mathrm{O}_{2}\right)$ and hydroxyl radicals. ROS can react with cellular lipids, deoxyribonucleic acid (DNA) and proteins to evoke lipid peroxidation, enzyme denaturation, mutagenesis and eventually cell death ${ }^{16,18}$. One of the determinants of extrinsic ageing processes are these oxidative reactions, which are catalysed in the presence of redox-active metal ions like $\mathrm{Fe}^{2+}$ and $\mathrm{Cu}^{2+}$, commonly found in the biological environment. All these factors, particularly UV, can modify the extracellular matrix (ECM) breaking down structural proteins such as collagen and elastin (Figure 1), which are the major components of the dermal tissue, essential for skin's structural stability and biomechanics ${ }^{17,19}$. ROS have been shown to upregulate the expression of several proteinases, including matrix metalloproteinases (MMP) and serine proteases, such as collagenase and elastase ${ }^{14}$. They were also reported to be involved in chronic inflammatory skin diseases, neurodegenerative disorders as well as in extrinsic ageing 9,17,20.

The search for new and more effective molecules from different sources has clearly been focussed on these potential mechanisms, with the goal of preventing oxidation, thus reducing the production of ROS and protecting the tissues ${ }^{14,21}$. Plants from the genus Plectranthus, belonging to the Lamiaceae family, are widely distributed across the warm and tropical areas of Africa, Asia and Oceania, and were likely brought to Mediterranean areas in the 16 th century during the period of Portuguese discoveries ${ }^{22,23}$. Rich in essential oils and in mono- and sesquiterpenes ${ }^{24-26}$, extracts from these plants are widely used in traditional medicine with different ethnopharmacological uses, including antimicrobial, analgesic, antipyretic, anti-inflammatory and antitumoral. Moreover, they have been applied in many skin disorders including wound healing ${ }^{25-28}$. Diterpenoids (abietane, labdane, kaurane, and clerodane skeleton), together with triterpenoids, phytosterols, phenolic acids, flavonoids and other polyphenolic compounds are the specific compounds of interest within this genus, according to their displayed effects compiled in the literature ${ }^{28-30}$. Polyphenols, such as rosmarinic acid which is ubiquous to all Plectranthus spp., and chlorogenic acid, obtained primarily from $P$. saccatus, and usually present in the aqueous extracts ${ }^{31-34}$, are powerful antioxidants ${ }^{17,22}$. Phenol groups in polyphenolic compounds are able to accept an electron to form relatively stable phenoxyl radicals, thereby disrupting radical chain oxidation reactions in cellular components $^{35}$. Abietane diterpenes from P. ecklonii, P. madagascariensis and $P$. grandidentatus are able to chelate the 2,2diphenyl-1-picrylhydrazyl (DPPH) radical comparably to positive control quercetin, a natural flavonoid ${ }^{23,33}$.

Another consequence of ROS overproduction on Caucasian skin is hyperpigmentation, frequently leading to lentigine lesions, freckles and melanoma ${ }^{21,36}$. All of these result from the stimulation of tyrosinase, a binuclear copper rate-limiting oxidase acting in the biosynthesis of melanin from L-tyrosine ${ }^{21,36-38}$. Overall, the chelating ability of Plectranthus spp., notably of $P$. ecklonii, $P$. madagascariensis and $P$. grandidentatus secondary metabolites, seems to be useful in a synergy for both antioxidant and anti-pigmentation skin treatment.

The degradation of the dermal ECM is also associated with these phenomena, such as the reduction or inhibition of collagenase and/or elastase activities, which might contribute to their prevention ${ }^{17,39}$. Recent studies have reported that many phenolic compounds isolated from plants with antioxidant properties, such as catechin and epigallocatechin gallate (EGCG), are also collagenase and/or elastase inhibitors. Inhibition usually involves metal chelation, making the catalytic $\mathrm{Zn}^{2+}$ of collagenase unavailable ${ }^{19,40}$. The hydrogen bonding between the hydroxyl groups of polyphenols and hydrogen bond donor or acceptor groups from elastase domains, hydrophobic interactions between the benzene rings of polyphenols and hydrophobic functional groups of the enzymes, and induced conformational changes ${ }^{17,37}$. Triterpenoids common to many plants, including some Plectranthus spp. such as $P$. neochilus, $P$. ornatus and $P$. ecklonii, are strong elastase and collagenase inhibitors ${ }^{20,36,40-42}$; they can bind reversibly to the catalytic sites of the enzymes, since an activity recovery has been observed upon dilution of the enzyme-inhibitor mixture ${ }^{43}$.

This study represents a primary evaluation of Plectranthus spp. extracts and isolated compounds as potential antioxidant agents capable of inhibiting the skin-related enzymes tyrosinase, collagenase and elastase, for the synergistic treatment of skin disorders, namely ageing, sagging and hyperpigmentation of the skin. Organic and aqueous extracts of several Plectranthus spp. plants, as well as their isolated compounds (Figure 2) were obtained, characterised and screened by our team, following the procedures described in previous phytochemical studies ${ }^{23,30-34,44-46}$. Their antioxidant and specific anti-enzymatic activities were tested in support of their potential interest for application in preventive dermatology and/or synergistic therapeutics. Furthermore, this is the first report on the in vitro activity of Plectranthus spp. extracts and isolated compounds as tyrosinase, collagenase and elastase inhibitors.

\section{Materials and methods}

\section{Reagents and enzymes}

2,2-Diphenyl-1-picrylhydrazyl (DPPH), quercetin, L-tyrosine, kojic acid, epigallocatechin gallate (EGCG), ursolic acid, $N$-[3-furylacryloyl]-Leu-Gly-Pro-Ala (FALGPA), $N$-succinyl-Ala-Ala- $p$-nitroanilide (SANA) and phosphate-buffered saline (PBS) were from SigmaAldrich. Tris(hydroxymethyl) aminomethane (Tris base buffer) was from Prolabo and tricine buffer was from Amresco. The enzyme elastase (EC 3.4.21.36) from porcine pancreas was purchased to Alfa Aesar, while tyrosinase (EC 1.14.18.1) from mushroom and collagenase (EC 3.4.24.3) from Clostridium histolyticum type IA were obtained from Sigma-Aldrich. Methanol, ethanol 70\% (w/v), dimethyl sulfoxide (DMSO), ethyl acetate and acetone were obtained from Merck.

\section{Plant material, extract preparation, and isolated compounds}

Plectranthus ( $P$. grandidentatus Gürke, $P$. ecklonii Benth., $P$. ornatus Codd., $P$. madagascariensis (Pers.) Benth., P. porcatus van Jaarsv. \& P.J.D. Winter, $P$. neochilus Schltr. and $P$. prostratus Gürke) medicinal plants from South Africa were cultivated at "Instituto Superior de Agronomia" campus (Lisbon). Extraction methods were performed according to previously established literature procedures, with slight modifications ${ }^{44}$.

The organic extracts were obtained from $100.010 \mathrm{~g}$ of air-dried aerial parts and powdered plants in $200 \mathrm{ml}$ of methanol, ethyl acetate or acetone after sonication at room temperature for $1 \mathrm{~h}$. The organic extracts were filtered and the solvent was removed in a rotary evaporator at $40-50^{\circ} \mathrm{C}$. The crude extracts (21 samples) were stored at $20 \mathrm{mg} / \mathrm{mL}$ in DMSO.

The aqueous extracts were obtained from $100.010 \mathrm{~g}$ of the aerial parts of dried and powdered plants in $150 \mathrm{ml}$ of bi-distilled 
<smiles>CC(=O)O[C@H]1C2=C(C(=O)C(O)=C(C(C)P)[C@@H]2O)[C@]2(C)CCCC(C)(C)[C@H]2[C@@H]1O</smiles><smiles>C=C1C=CC2=C(C(=O)C(O)=C(C(C)C)C2=O)[C@@]1(C)CCC</smiles><smiles>CC1=Cc2cc(C(C)C)cc(=O)c(O)c2[C@@]2(C)C[C@H](OC(=O)c3ccc(O)cc3)C[C@]1(C)C2</smiles>

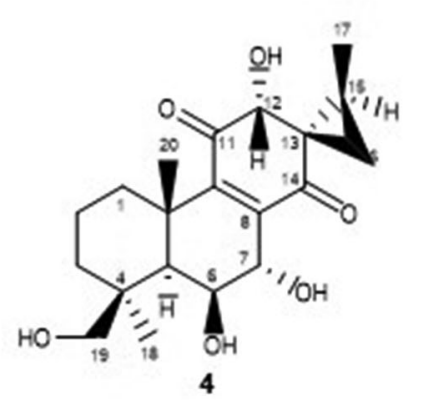

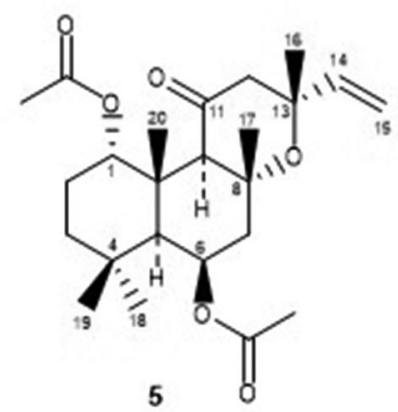

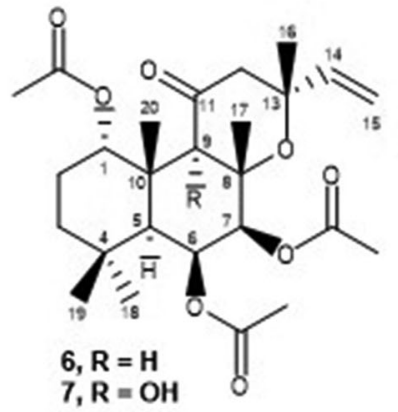<smiles>CC=C(C)C[C@H](C)[C@@H]1[C@@H](C)CC=C2[C@H]1CCC[C@H]2C</smiles>

8. $\mathbf{R} 1=\mathrm{COCH}_{3}, \mathbf{R} 2=\mathrm{COOH}$

9. $\mathbf{R}^{1}=\mathrm{COCH}_{2}, \mathbf{R}^{2}=\mathrm{COOCH}_{2}$ 10. $\mathrm{R} 1=\mathrm{H}, \mathrm{R}^{2}=\mathrm{CH}_{2} \mathrm{OH}$ 11. $R^{1}=\mathrm{H}, \mathbf{R}^{2}=\mathrm{CH}_{2} \mathrm{OCO}\left(\mathrm{CH}_{2}\right)_{2} \mathrm{CH}_{3}$

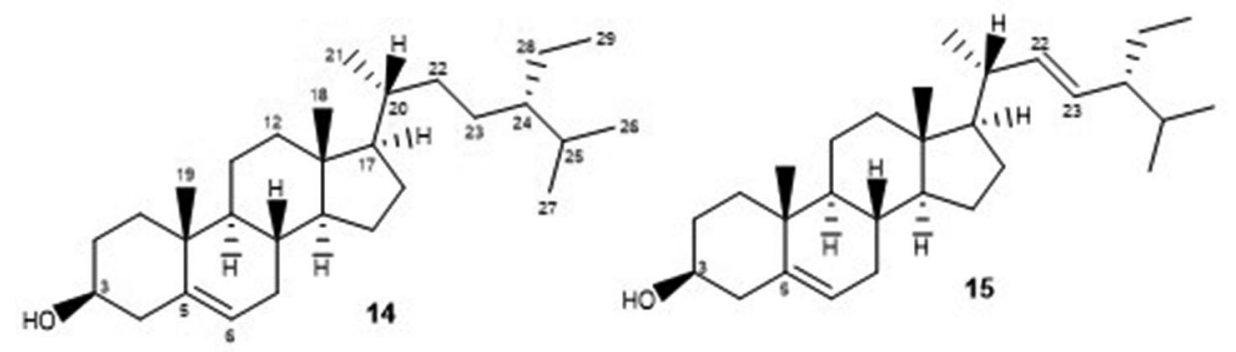<smiles>O=C(/C=C/c1ccc(O)c(O)c1)C[C@H](Cc1ccc(O)c(O)c1)C(=O)O</smiles>

Figure 1. Signalling pathway induced by ultraviolet (UV) radiation causing skin damage. Radical oxygen species (ROS) up-regulated mitogen activated protein kinases (MAPK) cascades enhance transcriptional activity of activator protein 1 (AP-1) heterodimer (comprised of c-Jun and c-Fos) thus increasing metalloproteinases (MPPs) expression. Additionally, transforming growth factor (TGF)-/Smad signalling pathway is down-regulated by over-accumulation of ROS, decreasing the synthesis of extracellular matrix (ECM) proteins such as collagenase and elastin.

water (Milli-Q) after microwave-assisted extraction for $3 \mathrm{~min}$ at a continuous irradiation of $2.45 \mathrm{GHz}$. The aqueous extracts (7 samples) were filtered and separated into $1 \mathrm{ml}$ aliquots (in triplicate) for freeze-drying and frozen at $-20^{\circ} \mathrm{C}$. After freeze-drying, the extracts were weighted and stored at $10 \mathrm{mg} / \mathrm{mL}$ in bi-distilled water (Milli-Q) at $-20^{\circ} \mathrm{C}$. The amount (dry weight) of each plant extract and yields according to solvent and extraction methodology are shown in Table 1. 
<smiles>CC(=O)O[C@H]1C2=C(C(=O)C(O)=C(C(C)P)C2=O)[C@@]2(C)CCCC(C)(C)[C@H]1[C@@H]2O</smiles><smiles>CC(F)C1=C(O)C(=O)C2=C(C1=O)[C@H](O)[C@H](O)[C@@H]1C(C)(C)CCC[C@@]21C</smiles><smiles>C=C1C(=O)C2=C(C(=O)C(O)=C(C(C)C)C2=O)[C@@]2(C)CCC[C@H](C)[C@@H]12</smiles><smiles>CC1=C2C=C(C(C)C)C(=O)C(O)=C2[C@@]2(C)C[C@H](OC(=O)c3ccc(O)cc3)CC(C)(C)C12</smiles>

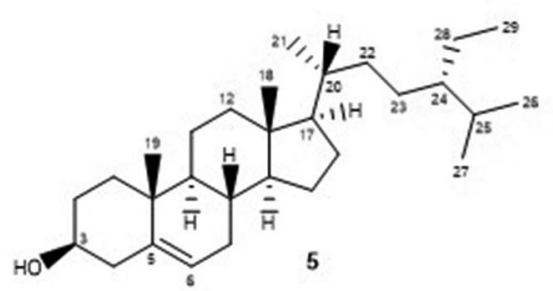

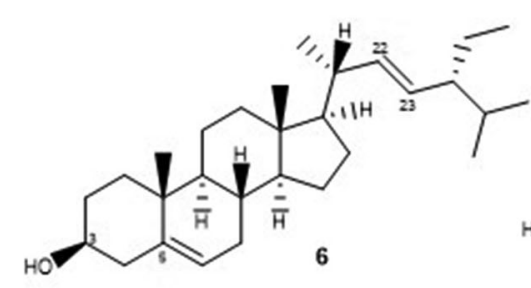

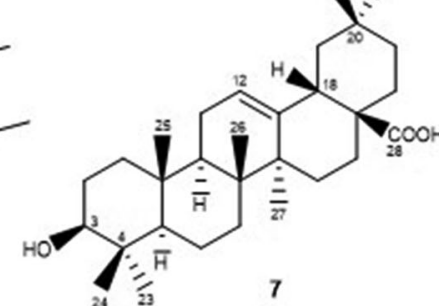

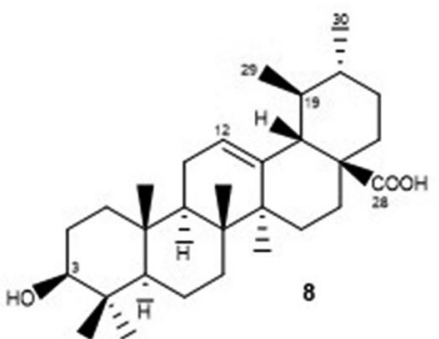

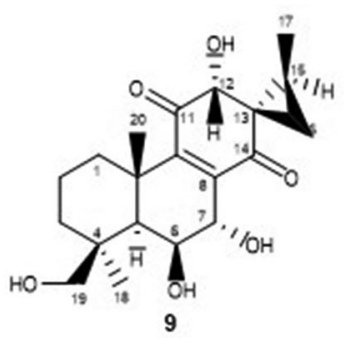

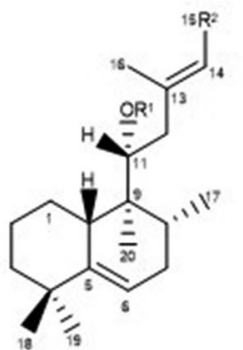

10. $R_{1}=\mathrm{COCH}_{2}, R_{2}=\mathrm{COOH}$

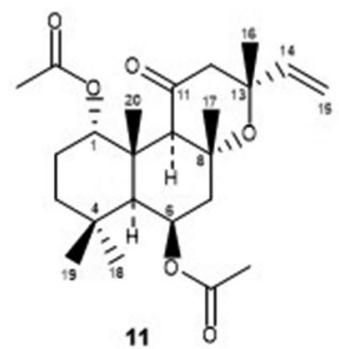<smiles>[Y6][R]([Y6])([H])O</smiles>

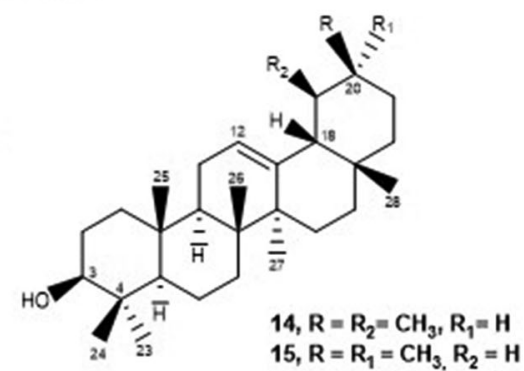<smiles>O=C(/C=C/c1ccc(O)c(O)c1)OC[C@H]1C[C@@](O)(C(=O)O)C[C@H](O)[C@H]1O</smiles>

16<smiles>O=C(/C=C/c1ccc(O)c(O)c1)C[C@H](Cc1ccc(O)c(O)c1)C(=O)O</smiles>

Figure 2. Studied natural compounds isolated from Plectranthus spp: 7-acetoxy-6-hydroxyroyleanone (1), 6,7-dihydroxyroyleanone (2), 6,7-dehydroroyleanone (3), Parvifloron D (4), -sitosterol (5), stigmasterol (6), oleanolic acid (7), ursolic acid (8), (13S,15S)-6,7,12,19-tetrahydroxy-13,16-cyclo-8-abietene-11,14-dione (9), (11 $\left.R^{*}, 13 E\right)$ 11-acetoxyhalima-5,13-dien-15-oic acid (10), Plectrornatin C (11), 1,6-di-O-acetylforskolin (12), 1,6-di-O-acetyl-9-deoxyforskolin (13), -amyrin (14), -amyrin (15), chlorogenic acid (16) and rosmarinic acid (17). 
Table 1. Amount of Plectranthus spp. extracts and yields according to the extraction solvent and extraction method (MW, microwave; US, ultrasound).

\begin{tabular}{llcc}
\hline Plectranthus spp. & Solvent (Method) & $\begin{array}{c}\text { Dry residue/g } \\
(0.001 \mathrm{~g})\end{array}$ & $\begin{array}{c}\text { Yield } \% \\
(\mathrm{mg} / 100 \mathrm{~g})\end{array}$ \\
\hline P. grandidentatus & Water (MW) & 0.028 & 0.27 \\
& Acetone (US) & 0.237 & 2.37 \\
& Methanol (US) & 0.686 & 6.76 \\
P. madagascariensis & Ethyl acetate (US) & 0.247 & 2.45 \\
& Water (MW) & 0.031 & 0.31 \\
& Acetone (US) & 0.203 & 2.03 \\
& Methanol (US) & 0.823 & 8.21 \\
P. ecklonii & Ethyl acetate (US) & 0.236 & 2.35 \\
& Water (MW) & 0.034 & 0.34 \\
& Acetone (US) & 0.384 & 3.83 \\
P. porcatus & Methanol (US) & 0.949 & 9.45 \\
& Ethyl acetate (US) & 0.332 & 3.32 \\
& Water (MW) & 0.026 & 0.26 \\
P. ornatus & Acetone (US) & 0.662 & 6.59 \\
& Methanol (US) & 1.233 & 12.30 \\
& Ethyl acetate (US) & 0.704 & 7.00 \\
& Water (MW) & 0.043 & 0.43 \\
P. neochilus & Acetone (US) & 6.000 & 59.90 \\
& Methanol (US) & 1.059 & 10.60 \\
& Ethyl acetate (US) & 0.924 & 9.15 \\
P. prostratus & Water (MW) & 0.032 & 0.32 \\
& Acetone (US) & 0.430 & 4.26 \\
& Methanol (US) & 1.040 & 10.40 \\
& Ethyl acetate (US) & 0.552 & 5.51 \\
& Water (MW) & 0.033 & 0.33 \\
& Acetone (US) & 0.819 & 8.16 \\
& Methanol (US) & 1.189 & 11.80 \\
& Ethyl acetate (US) & 0.951 & 9.48 \\
& Acetone (US) & 0.689 & 6.89 \\
\hline & & & \\
& & & \\
& & &
\end{tabular}

The natural compounds tested (Figure 2), previously isolated from Plectranthus spp. using bioassay-guided fractionation of extracts, were the abietane diterpenoids 7-acetoxy-6-hydroxyroyleanone (1) from $P$. grandidentatus ${ }^{34,46}$, 6,7-dihydroxyroyleanone (2) and 6,7-dehydroroyleanone (3) from $P$. madagascariensis ${ }^{22}$, Parvifloron D (4), the phytosterol 1:1 mixture of -sitosterol (5) and stigmasterol (6), and the 4:1 mixture of oleanolic (7) and ursolic acids (8), from $P$. ecklonii ${ }^{31,46}$, (13S,15S)-6,7,12,19-tetrahydroxy13,16-cyclo-8-abietene-11,14-dione (9) from $P$. porcatus ${ }^{32}$, the halimane diterpene $\left(11 R^{*}, 13 E\right)$-11-acetoxyhalima-5,13-dien-15-oic acid (10), the labdane diterpenoids Plectrornatin $C(\mathbf{1 1})$ and the $1: 1$ mixture of 1,6-di-O-acetylforskolin (12) and 1,6-di-O-acetyl-9-deoxyforskolin (13), the triterpene 3:1 mixture of -amyrin (14) and -amyrin (15) from $P$. ornatus ${ }^{30,33,45,47}$, chlorogenic acid (16) from $P$. saccatus $^{22}$ and rosmarinic acid (17), the main polyphenol isolated from the aqueous extracts of Plectranthus spp. ${ }^{44}$. The chemical structures of these compounds have been established by comparing their spectral data with those in the literature and/or with authentic samples isolated by our group.

\section{Antioxidant activity assay}

The free radical scavenging activity of the organic extracts $(100 \mathrm{~g} / \mathrm{mL})$ was evaluated by the DPPH assay according to literature procedures ${ }^{33,48}$. All extracts were dissolved in ethanol $70 \%(\mathrm{w} / \mathrm{v})$, mixed with DPPH solution (100 mM in ethanol) and incubated at room temperature for $30 \mathrm{~min}$, in the dark. The absorbance of the solutions was read at $517 \mathrm{~nm}$ (Perkin-Elmer Lambda 2 UV-vis spectrophotometer) against a blank containing the same concentration of the organic extracts in ethanol. Quercetin $\left(\mathrm{IC}_{50}=10.31 .5 \mathrm{~g} / \mathrm{mL}\right)$ was used as positive control while negative control corresponded to DPPH in ethanol. Radical scavenging activity (RSA, \%) was determined from Equation (1).

$$
\operatorname{RSA}(\%)=\operatorname{Abs}_{(\mathrm{DPPH})}-\left[\left(\operatorname{Abs}_{(\text {sample })}-\operatorname{Abs}_{(\text {blank })}\right) / \operatorname{Abs}_{(\mathrm{DPPH})}\right] 100
$$

\section{Enzyme inhibitory assays}

\section{Anti-tyrosinase activity assay}

The isolated compounds (Figure 2) and extracts (both organic and aqueous) from the described Plectranthus plants were tested in the anti-tyrosinase activity assay with modifications ${ }^{15}$. The assay was performed using $180 \mathrm{~L}$ of the substrate L-tyrosine $(0.5 \mathrm{mM})$ in PBS $50 \mathrm{mM}(\mathrm{pH} 6.8)$ and $10 \mathrm{~L}$ of the tested samples $(50 \mathrm{~g} / \mathrm{mL})$ incubated for $5 \mathrm{~min}$ at $37 \mathrm{C}$ before starting the reaction by adding $10 \mathrm{~L}$ of tyrosinase $(5000 \mathrm{U})$. After incubation at $37 \mathrm{C}$ for $5 \mathrm{~min}$, production of dopachrome was detected from absorbance measurements at $450 \mathrm{~nm}$ every $2 \mathrm{~min}$, for $10 \mathrm{~min}$, in a microplate reader (Thermo-Fisher Scientific). Kojic acid $(0.8 \mathrm{mM})$ was used as positive control, with reported $I_{50}$ of $43.7 \mathrm{M}^{49}$, and sample solvent (DMSO $0.5 \%(\mathrm{v} / \mathrm{v})$ in PBS buffer) as negative control. All assays were performed in triplicate. Results were expressed as percentage inhibition (\%) determined from Equations (2) and (3). The absorbance variation (Abs) registered by Equation (2) for enzyme velocity reaction of negative control (Abs/time) must be in the linear range.

$$
\begin{aligned}
& \text { Velocity reaction of control or inhibitor }=\text { Abs/time }(\min ) \\
& \text { Inhibitory activity }(\%)= \\
& \quad 100-(100 \text { velocity reaction } \\
& \left.(\text { inhibitor })_{1}\right) / \text { velocity reaction }_{(\text {control })}
\end{aligned}
$$

\section{Anti-collagenase activity assay}

The anti-collagenase enzymatic assay was optimised based on several methods reported in the literature ${ }^{16,17,40,50}$. The synthetic substrate $\mathrm{N}$-[3-furyl-acryloyl]-Leu-Gly-Pro-Ala (FALGPA) $0.1 \mathrm{mM}$ was dissolved in tricine buffer $50 \mathrm{mM}(\mathrm{pH}$ 7.5) supplemented with $400 \mathrm{mM}$ sodium chloride $(\mathrm{NaCl})$ and $10 \mathrm{mM}$ calcium chloride $\left(\mathrm{CaCl}_{2}\right)$ (assay buffer). Collagenase was prepared in the assay buffer at $1 \mathrm{U}$, knowing that $1 \mathrm{U}$ hydrolyses $1 \mathrm{~mol}$ of FALGPA per minute, at $25^{\circ} \mathrm{C}$, in the presence of calcium ions. EGCG at $40 \mathrm{M}$ was used as positive control with reported $\mathrm{IC}_{50}$ of $0.9 \mathrm{mM}^{51}$, and the sample solvent (DMSO $0.3 \% \mathrm{v} / \mathrm{v}$ in tricine buffer) as the negative control. The assay mixture containing $80 \mathrm{~L}$ of tested samples $(100 \mathrm{~g} / \mathrm{mL})$ and $100 \mathrm{~L}$ of collagenase was incubated at $37^{\circ} \mathrm{C}$ for $10 \mathrm{~min}$ before starting the reaction by adding $20 \mathrm{~L}$ of FALGPA. The assay was performed in triplicate. Absorbance of FALGPA was read at $405 \mathrm{~nm}$ for $10 \mathrm{~min}$, continuously, in a microplate reader (Thermo-Fisher Scientific). Results were expressed as percentage inhibition (\%), according to Equations (2) and (3).

\section{Anti-elastase activity assay}

The anti-elastase enzymatic assay was based on spectrophotometric methods described in the literature, with some modifications ${ }^{16,17,19,52}$. The substrate $N$-succinyl-Ala-Ala-Ala- $p$-nitroanilide (SANA) $1 \mathrm{mM}$ was dissolved in Tris- $\mathrm{HCl}$ buffer $50 \mathrm{mM}(\mathrm{pH} 8.0)$ knowing that $1 \mathrm{U}$ enzyme (elastase) converts $1 \mathrm{~mol}$ of SANA per minute in this buffer at $25^{\circ} \mathrm{C}$. Ursolic acid $(100 \mathrm{~g} / \mathrm{mL})$ was used as positive control with reported $I C_{50}$ of $10 \mathrm{M}^{19}$, and the sample 


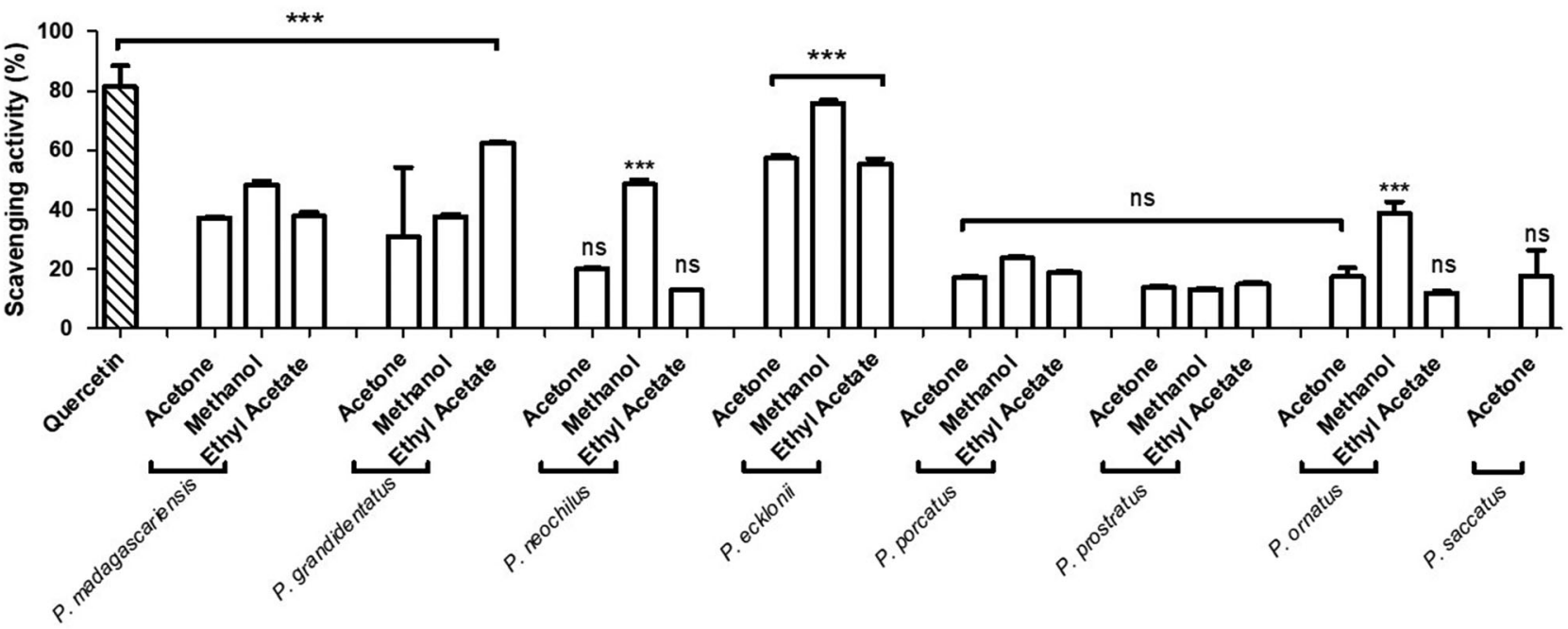

Figure 3. In vitro antioxidant activity of Plectranthus spp. organic extracts at $100 \mathrm{~g} / \mathrm{mL}$ measured as percentage of DPPH radical scavenging activity. The results are presented as means percentage values, considering the absorbance of quercetin as the positive control. Data are expressed as the mean \pm SD $(n=3) * * p<0.005$ $*_{* *} p<0.0001$ vs negative control (DPPH in ethanol). DPPH: 2,2-diphenyl-1-picrylhydrazyl; ns: not significant; SD: Standard Desviation. Values were determined by oneway ANOVA followed by Tukey HSD comparison test.

solvent (DMSO 1\% (v/v) in Tris-HCl buffer) as negative control. The reaction was initiated by adding $20 \mathrm{~L}$ of SANA and $150 \mathrm{~L}$ of Tris$\mathrm{HCl}$ buffer followed by addition of elastase $(6 \mathrm{U})$ and the samples $(100 \mathrm{~g} / \mathrm{mL})$. The mixture was incubated at $25^{\circ} \mathrm{C}$ for $10 \mathrm{~min}$. Formation of $p$-nitroaniline from SANA hydrolysis was detected from absorbance measurements at $405 \mathrm{~nm}$, performed immediately after starting the reaction and then every $30 \mathrm{~s}$ for $3 \mathrm{~min}$, in a microplate reader (Thermo-Fisher Scientific). All assays were performed in triplicate. Results were expressed as percentage inhibition (\%) according to Equations (2) and (3).

\section{Statistical analysis}

Data comparisons were conducted with one-way analysis of variance (ANOVA) followed by post-hoc Tukey honest significant difference test, for pairwise comparisons. Analysis and graphical presentation were performed with the GraphPad Prism Software Version 5 (GraphPad Software, Inc., San Diego, CA, USA). Values of $p<0.05$ were statistically significant. Results were presented as mean standard deviation (SD).

\section{Results}

\section{Antioxidant activity}

The antioxidant activity of several Plectranthus spp. organic extracts was evaluated concerning their ability for scavenging the DPPH radical, using quercetin as positive control. The results, expressed in percentage of RSA, are shown in Figure 3.

\section{Inhibition of skin-related enzymes}

\section{In vitro tyrosinase inhibition}

The present study performed a screening of several Plectrathus spp. extracts (both aqueous and organic) and previously isolated secondary metabolites regarding their in vitro inhibition of skinrelated enzymes, namely tyrosinase, collagenase and elastase.

In the in vitro anti-tyrosinase assay, the enzymatic activity was evaluated by using L-tyrosine as substrate and detecting the produced chromophore (dopachrome) at $450 \mathrm{~nm}^{49}$ as described in
Materials and Methods - Anti-tyrosinase Activity Assay. The results obtained for the Plectranthus spp. organic extracts shown in Figure $4(\mathrm{~A})$, expressed as percentage of inhibition of tyrosinase activity, ranged from 25 to $68 \%$ compared to $92.97 .4 \%$ obtained for kojic acid, used as positive control.

Aiming at a more extensive comprehension of the agents causing tyrosinase inhibition, the aqueous extracts obtained from Plectranthus spp. were additionally tested, and the results obtained, presented in Figure 4(B), revealed that in contrast with the organic extracts, the aqueous extracts were less effective as tyrosinase inhibitors.

To better understand the observed results, an additional assay was performed to evaluate which natural products present in the organic and aqueous extracts could be responsible for the exhibited anti-tyrosinase activity. Thus, previously isolated compounds from both organic and aqueous extracts of Plectranthus spp. were tested for their ability to inhibit tyrosinase in vitro, and the results obtained are shown in Figure 4(C).

In vitro collagenase inhibition

Evaluation of the in vitro anti-collagenase activity of Plectranthus spp. extracts and isolated compounds was performed using FALGPA as substrate and measuring the collagenase $(\mathrm{ChC})$ activity by the decrease in absorbance at $405 \mathrm{~nm}$ due to FALGPA hydrolysis as described in Materials and Methods - Anti-collagenase Activity Assay. Figure 5(A) represents the results obtained for the organic extracts, expressed as percentage inhibition, revealing a mild to high ChC inhibitory activity, ranging from $28 \%$ to $76 \%$, compared with EGCG used as positive control.

The aqueous extracts from Plectranthus spp., characterised by high amounts of phenolic compounds, which have been described as collagenase inhibitors ${ }^{14}$, were also studied for $\mathrm{ChC}$ inhibition, and results are displayed in Figure 5(B).

Since both organic and aqueous extracts from Plectranthus spp. in general exerted an inhibitory effect on collagenase, isolated compounds were further tested in order to determine their contribution for the enzymatic inhibition observed, and results obtained are exhibited in Figure 5(C). 


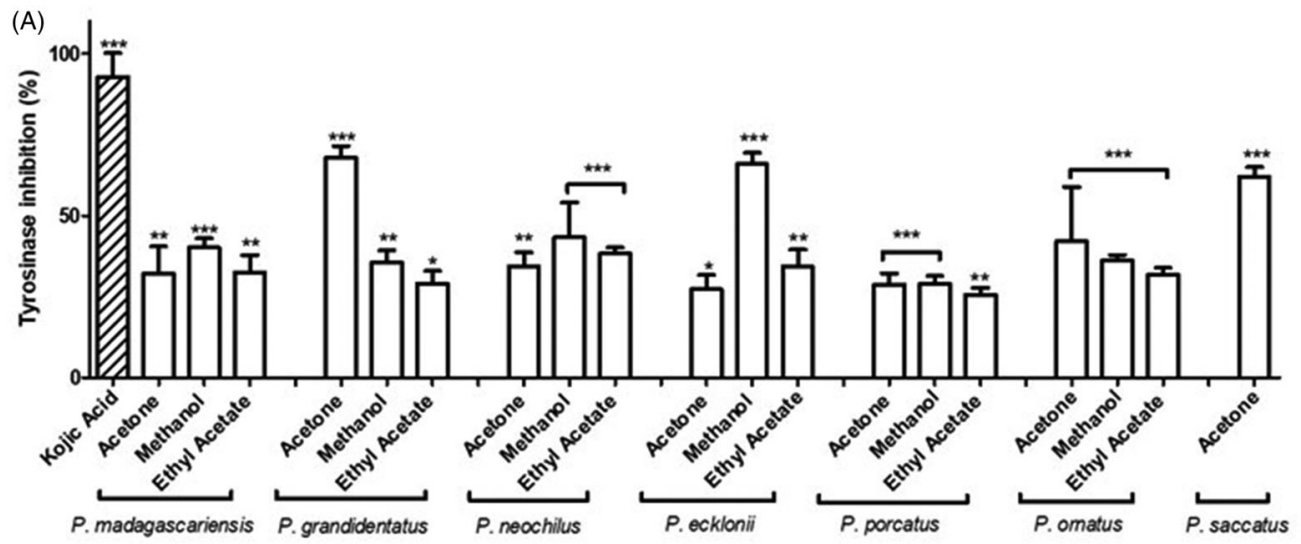

(B)

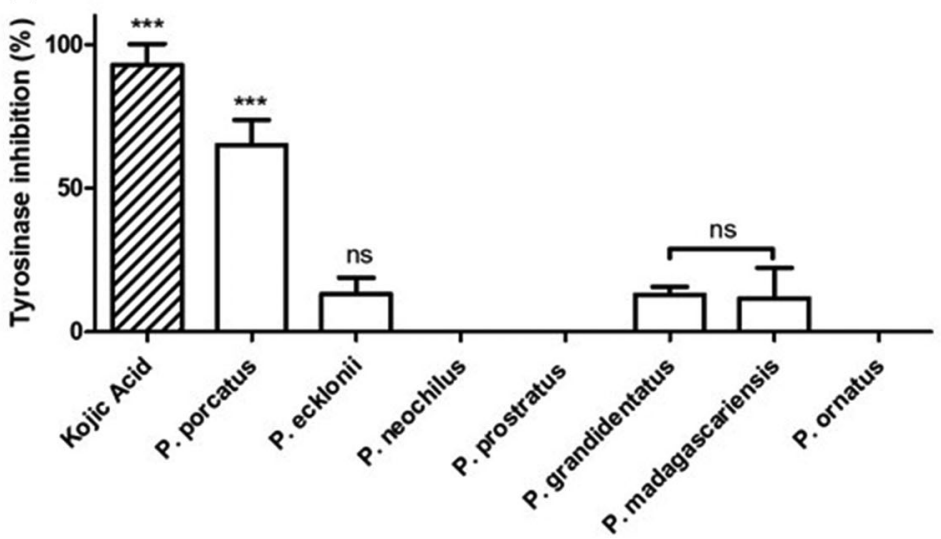

(C)

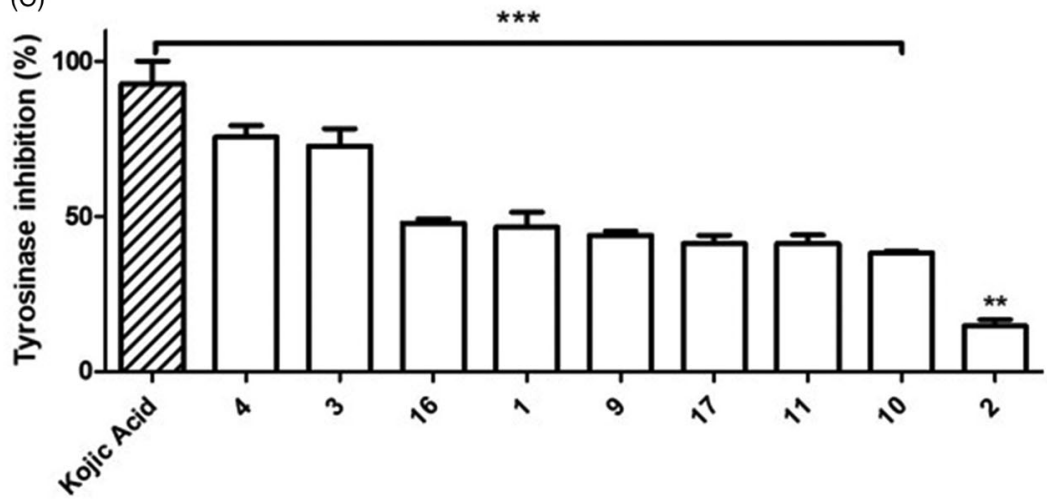

Figure 4. In vitro anti-tyrosinase activity of Plectranthus spp. (A) Organic extracts at $50 \mathrm{~g} / \mathrm{mL}$. (B) Aqueous extracts at $50 \mathrm{~g} / \mathrm{mL}$. (C) Isolated compounds at $50 \mathrm{~g} / \mathrm{mL}$. The results are presented as means percentage values, considering the absorbance of kojic acid as the positive control. Data are expressed as the mean \pm SD ( $n=3$ ) ${ }^{*} p<0.05{ }^{* *} p<0.005{ }^{* * *} p<0.0001$ vs negative control (DMSO 0.5\% (v/v) in PBS buffer). DMSO: dimethyl sulfoxide; ns: not significant; PBS: phosphate-buffered saline; SD: Standard Deviation. Values were determined by one-way ANOVA followed by Tukey HSD comparison test.

In vitro elastase inhibition

The anti-elastase activity of Plectranthus spp. extracts and isolated compounds was evaluated in vitro using SANA as substrate and detecting the formation of $p$-nitroaniline at $405 \mathrm{~nm}$ resulting from SANA hydrolysis, as described in the Materials and Methods - Antielastase Activity Assay, using ursolic acid as positive control. Results of the enzymatic assay concerning the organic extracts from Plectranthus spp. plants are expressed in Figure 6(A), revealing in general very weak elastase inhibitory activity.

Since polyphenolic compounds have been suggested to possess anti-elastase activity ${ }^{20}$, the aqueous extracts expected to have this type of compounds were tested and the results are shown in Figure 6(B).
Although aqueous extracts from Plectranthus spp. plants were also not effective as elastase inhibitors $(p>0.05)$, according to Figure 5(B), the isolated compounds were still further assessed for their ability to inhibit elastase and results are displayed in Figure 6(C).

\section{Discussion}

\section{Antioxidant activity}

The antioxidant properties of Plectranthus spp. organic extracts were evaluated based on their scavenging activity for the DPPH radical. According to Figure 3 , the methanolic extracts held the highest RSA (20-76\%) among the organic extracts, except for the 
(A)

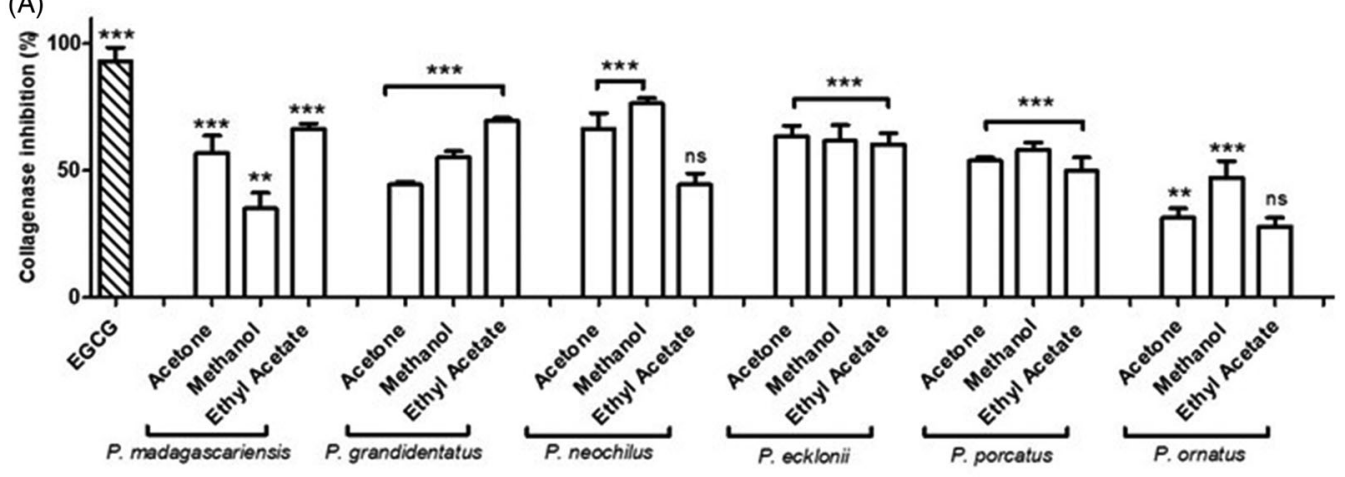

(B)

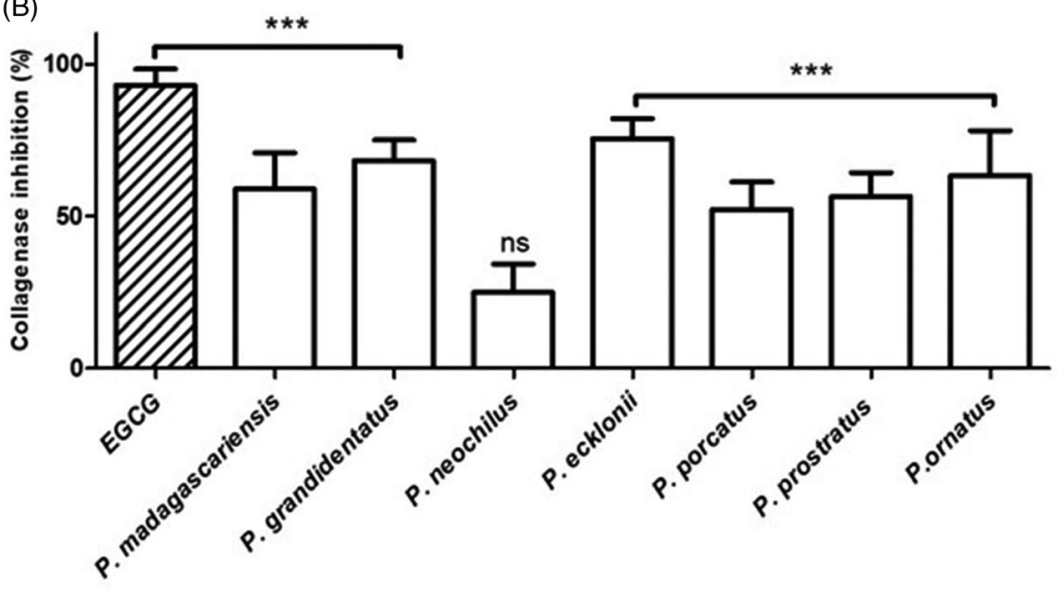

(C)

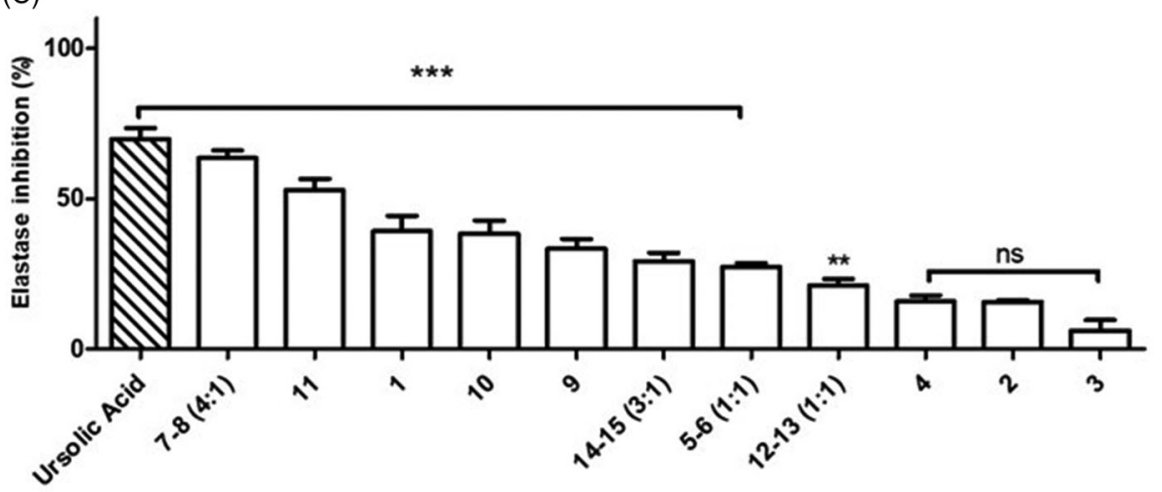

Figure 5. In vitro anti-collagenase activity of Plectranthus spp. (A) Organic extracts at $100 \mathrm{~g} / \mathrm{mL}$. (B) Aqueous extracts at $100 \mathrm{~g} / \mathrm{mL}$. (C) Isolated compounds at $100 \mathrm{~g} / \mathrm{mL}$. The results are presented as means percentage values, considering the absorbance of EGCG as the positive control. Data are expressed as the mean \pm SD ( $n=3$ ) $*_{* *} p<0.0001$ vs negative control (DMSO $0.3 \%$ (v/v) in Tricine buffer). DMSO: dimethyl sulphoxide; EGCG: epigallocatechin gallate; ns: not significant; SD: Standard Deviation. Values were determined by one-way ANOVA followed by Tukey HSD comparison test.

ethyl acetic extract from $P$. grandidentatus, with a RSA of 62.3 $0.4 \%$. The observed results are possibly related with the high content of polyphenols usually present in the methanolic extracts, which are known for their antioxidant activity ${ }^{53}$. Nevertheless, recent findings concerning the antioxidant activity of abietane diterpenes, namely compounds (1) and $(\mathbf{4})^{23}$, which have been isolated from Plectranthus spp., suggest that these compounds may also contribute to the observed bioactivity. The quinone moiety present in abietane diterpenes is probably responsible for their biological activity, since quinones represent important features at stabilising free radicals in many biological systems suffering from oxidative stress, protein inactivation and intermediate melanin synthesis pathway in human $\operatorname{skin}^{54,55}$.

The antioxidant results obtained for the methanolic extracts of P. ecklonii (75.9 1.0\%) and P. madagascariensis (48.4 1.2\%) as well as for the ethyl acetic extract of $P$. grandidentatus $(62.30 .4 \%)$ can also be explained by their main diterpenoid compounds with an abietane backbone associated with antioxidant activity ${ }^{23}$. Additionally, P. ecklonii ethyl acetic (55.5 1.7\%) and acetonic (56.9 $1.5 \%)$ extracts showed relatively higher RSA when compared to the remaining Plectranthus spp. extracts, which held high RSA values only for the methanolic extracts. Actually, $P$. ecklonii and 


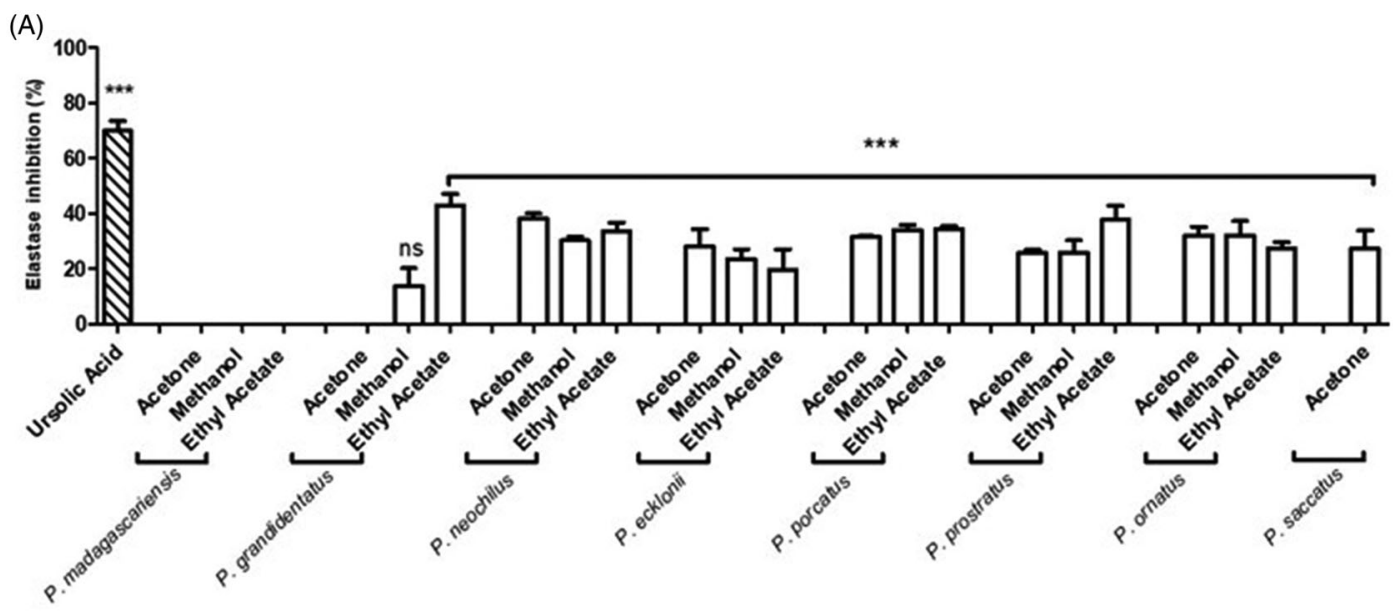

(B)
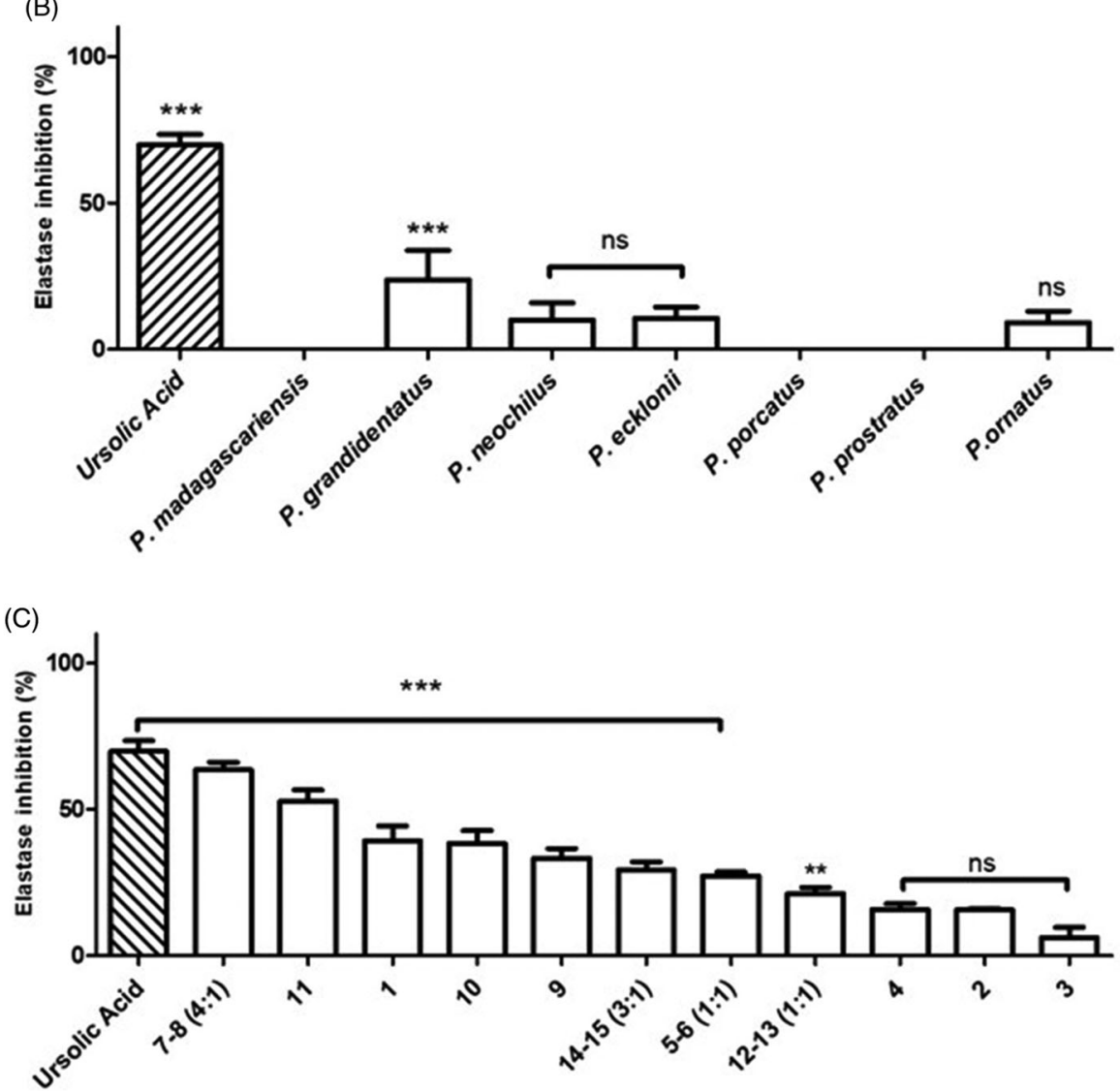

Figure 6. In vitro anti-elastase activity of Plectranthus spp. (A) Organic extracts at $100 \mathrm{~g} / \mathrm{mL}$. (B) Aqueous extracts at $100 \mathrm{~g} / \mathrm{mL}$. (C) Isolated compounds at $100 \mathrm{~g} / \mathrm{mL}$. The results are presented as means percentage values, considering the absorbance of ursolic acid as the positive control. Data are expressed as the mean \pm SD $(n=3)$ ${ }^{* * *} p<0.0001$ vs negative control (DMSO 1\% (v/v) in Tris-HCl buffer). DMSO: dimethyl sulphoxide; HCl: Hydrochloride; ns: not significant; SD: Standard Deviation; Tris: tris(hydroxymethyl) aminomethane. Values were determined by one-way ANOVA followed by Tukey HSD comparison test.

P. grandidentatus had the highest antioxidant activity among the studied Plectranthus species, with RSA similar to that of quercetin $(89.02 .5 \%)$ used as positive control, which is a potent antioxidant flavonoid compound ${ }^{23,33}$.

Recently there has been an increased concern about synthetic antioxidants, such as the widely used butylated hydroxyanisole (BHA) and butylated hydroxytoluene (BHT), which are suspected to induce liver damage and carcinogenesis in animals ${ }^{39}$. Therefore, less cytotoxic and eventually more powerful antioxidants from natural sources, such as Plectranthus plants, represent promising alternatives.

\section{In vitro inhibition of skin-related enzymes}

\section{Tyrosinase inhibition}

The Plectranthus spp. extracts and isolated compounds have been evaluated as tyrosinase inhibitors. The organic extracts showed promising results (Figure $4(A)$ ) with inhibitory activity as high as $68 \%$ compared to $92.97 .4 \%$ obtained for kojic acid used as positive control. According to the results obtained (Figure $4(A)$ ), the methanolic (25-66\%) and acetonic (27-68\%) extracts exhibited the highest tyrosinase inhibition activity $(p<0.05)$. High tyrosinase inhibition was observed for the $P$. grandidentatus acetonic (67.9 
3.6\%), P. ecklonii methanolic (65.9 3.4\%) and $P$. saccatus acetonic (56.4 5.7\%) extracts. Moreover, P. grandidentatus and $P$. ecklonii showed the highest anti-tyrosinase activity in vitro, and these were also the plants that showed increased antioxidant activity. The observed results can be attributed to the abietane diterpenoids mainly present in the organic extracts of these two plants ${ }^{23,33}$.

In contrast with the organic extracts, the aqueous extracts (Figure $4(B))$ were less effective as tyrosinase inhibitors $(p>0.05)$, except for the aqueous extract of $P$. porcatus $(p<0.0001)$, showing tyrosinase inhibition of $65.08 .7 \%$ in comparison with $92.97 .4 \%$ obtained for kojic acid used as positive control. Actually, the $P$. porcatus aqueous extracts obtained with microwave extraction have been previously characterised by high-performance liquid chromatography (HPLC) concerning quantification of polyphenols ${ }^{22}$. The obtained HPLC profile revealed that $P$. porcatus aqueous extracts have some amounts of rosmarinic acid (17) and caffeic acid, however $P$. ecklonii and $P$. saccatus had the highest polyphenol content ${ }^{22}$. Therefore, it can only be suggested that the anti-tyrosinase activity of the aqueous extract of $P$. porcatus is probably due to a synergistic effect of the present compounds.

Further evaluation of the effects on tyrosinase activity of isolated compounds from both organic and aqueous extracts (Figure $4(C))$ confirm some of the high inhibition values previously found for the extracts. Notably, the abietane diterpenes (1), (3) and (4) present mainly in $P$. grandidentatus, $P$. madagascariensis, and $P$. ecklonii organic extracts, are able to inhibit tyrosinase activity in more than $46 \%$ and up to $75 \%$. Moreover, it is possible to better understand the activity of the $P$. porcatus aqueous extract according to the result obtained for compound (9) which inhibited tyrosinase activity by $43.91 .3 \%$. Although this compound is mainly isolated from the acetone extract of $P$. porcatus, which showed low tyrosinase inhibition (28.8 3.4\%, Figure $4(A))$, its presence in the aqueous extract cannot be excluded since the microwave aqueous extraction method has a higher efficiency in the recovery of bioactive compounds ${ }^{22}$. Additionally, (16) and (17) were able to inhibit tyrosinase by $47.91 .4 \%$ and $40.40 .7 \%$, respectively. However, these compounds are not present in high amounts in $P$. porcatus aqueous extracts, therefore it can only be suggested that the extract activity was probably due to the presence of compound (9). Overall, the results suggest that Plectranthus spp. polyphenols and abietane diterpenes are capable of inhibiting tyrosinase being almost as efficient as kojic acid used as positive control.

Although neither the mechanism of inhibition nor the type of inhibition were studied, the most potent tyrosinase inhibitors such as hydroquinone, kojic acid, azelaic acid and other electron-rich phenols, have been reported for their capability of inhibiting melanin overproduction ${ }^{21,37}$. However, the use of these compounds in the fight against skin ageing and hyperpigmentation is limited due to their adverse side effects, low formulation stability, and poor skin penetration, hence the search for new agents from natural products.

Hydroquinones and phenols, part of the chemical structure of abietane diterpenes (1-4), (16) and (17), have been recognised for their chelating ability ${ }^{21}$, which can probably explain their high anti-tyrosinase activity. Moreover, due to the presence of polyphenolic compounds such as chlorogenic acid (16) and quercetin, other plants have been used for the treatment of skin depigmentation ${ }^{14}$. Actually, quercetin, a strong antioxidant flavonoid compound, has been reported to be a strong inhibitor of tyrosinase, with an $\mathrm{IC}_{50}$ of $0.10 \mathrm{mM}^{37}$. This strongly suggests that the observed synergistic effect of Plectranthus spp. natural products with both antioxidant and anti-tyrosinase inhibitor properties can be useful for anti-pigmentation skin treatment.

\section{Collagenase inhibition}

The organic extracts from Plectranthus spp. exhibited mild to high ChC inhibitory activity, in the range $28-76 \%$ (Figure 5(A)). The highest anti-collagenase activity was observed for $P$. neochilus methanolic extract $(76.4$ 2.1\%) in comparison with the positive control EGCG (93.1 5.3\%). Additionally, the organic extracts of $P$. madagascariensis, $P$. grandidentatus, and $P$. ecklonii were effective at inhibiting $\mathrm{ChC}$ in more than $60 \%$.

The obtained results for the $P$. neochilus organic extracts strongly suggest that the anti-ChC activity observed is mainly due to pentacyclic triterpenes typically present, particularly (14) and (15), previously reported as ChC inhibitors ${ }^{43}$. On the other hand, the high inhibition of $P$. ecklonii organic extracts is most likely due to the presence of other pentacyclic triterpenes, such as (7) and (8) and/or abietane diterpenoids (1-4). Actually, compounds (7), (8), (14) and (15) have been widely studied for their ability to inhibit both collagenase and elastase, possibly by reversibly binding to the catalytic sites of these enzymes ${ }^{19,36,43}$.

Phenolic compounds have also been described as collagenase inhibitors ${ }^{14}$, thus the aqueous extracts from Plectranthus spp. containing the larger amounts of these compounds were also evaluated for ChC inhibition (Figure 5(B)). In contrast with the organic extracts, the $P$. neochilus aqueous extract was the lowest ChC inhibitor (24.9 9.4\%), although the remaining aqueous extracts revealed more promising results, the highest inhibition (75.6 6.5\%) being obtained for the $P$. ecklonii aqueous extract.

Previous studies concerning polyphenols quantification in Plectranthus spp. plants have established that $P$. ecklonii aqueous extracts obtained from microwave extraction had one of the highest contents on compound (17) $)^{34}$. This study helps to understand the high collagenase activity observed for the $P$. ecklonii aqueous extract since many polyphenolic compounds, such as catechin and EGCG, have been reported to inhibit collagenase ${ }^{40}$, probably by acting as metal chelators, making the $\mathrm{Zn}^{2+}$ ion unavailable for catalytic activity ${ }^{19,40}$.

In general, both organic and aqueous extracts from Plectranthus spp. exerted an inhibitory effect on collagenase, thus isolated compounds were further tested (Figure $5(C)$ in order to determine their contribution for the enzymatic inhibition observed. According to Figure $5(C)$, the diterpene abietanes (3) and (4) mainly isolated from organic extracts along with (17), the major polyphenol present in the aqueous extracts, showed the highest ability for collagenase inhibition. Notably, compound (4) was found to inhibit $\mathrm{ChC}$ by $84.65 .9 \%$, being almost as efficient as positive control EGCG (93.1 5.3\%). To our knowledge, this is the first report on the in vitro inhibition of $\mathrm{ChC}$ by diterpenes with an abietane backbone.

On the other hand, the royleanones (1) and (2) inhibited $\mathrm{ChC}$ by only $33.53 .3 \%$ and $24.03 .0 \%$, respectively. These compounds are also abietane diterpenes, but with a royleanone motif that may be lowering the inhibitory capacity when compared to (4), whose structure includes different donor atoms resulting in higher metal chelation ability ${ }^{23}$. Compound (17) inhibited collagenase by $44.84 .5 \%$ suggesting the presence of other polyphenols, such as compound (16) or caffeic acid, in the aqueous extracts of Plectranthus spp. to possibly justify the reported activity in Figure 5(B). Overall, Plectranthus spp. plants are highly promising natural sources for developing potential cosmetic agents against skin ageing induced by increased collagenase activity. 
Table 2. In vitro enzymatic inhibition (\%) of tyrosinase, collagenase and elastase by isolated compounds from Plectranthus spp.

\begin{tabular}{|c|c|c|c|}
\hline \multirow[b]{2}{*}{ Compound No. } & \multicolumn{3}{|c|}{ Enzymatic inhibition SD (\%) } \\
\hline & Anti-tyrosinase $^{a}$ & Anti-collagenase $^{\mathrm{b}}$ & Anti-elastase $^{\mathrm{b}}$ \\
\hline 1 & 46.64 .7 & 33.53 .2 & 29.32 .8 \\
\hline 2 & 14.72 .0 & 24.03 .0 & 39.25 .2 \\
\hline 3 & 75.73 .6 & 60.69 .7 & 38.34 .4 \\
\hline 4 & 72.75 .6 & 84.65 .9 & 52.83 .8 \\
\hline 5-6 (1:1 mixture) & NT & NT & NT \\
\hline 7-8 (1:4 mixture) & NT & NT & 63.52 .6 \\
\hline 9 & 43.91 .3 & 24.69 .2 & 21.22 .1 \\
\hline 10 & 38.30 .6 & 41.54 .9 & 27.31 .4 \\
\hline 11 & 41.32 .7 & 16.71 .9 & 33.33 .3 \\
\hline 12-13 (1:1 mixture) & NT & NT & 6.153 .5 \\
\hline 14-15 (3:1 mixture) & NT & NT & 15.82 .0 \\
\hline 16 & 40.40 .7 & NT & NT \\
\hline 17 & 47.91 .4 & 44.84 .5 & NT \\
\hline Positive control (compound) & 92.97 .4 (Kojic acid) & 93.15 .3 (EGCG) & 69.93 .7 (Ursolic acid) \\
\hline
\end{tabular}

${ }^{a}$ Samples tested at $50 \mathrm{~g} / \mathrm{mL}$, ${ }^{\mathrm{b}}$ samples tested at $100 \mathrm{~g} / \mathrm{mL}$, NT, not tested; for compound number chemical structure assignments refer to Table 1. EGCG: epigallocatechin gallate.

\section{Elastase inhibition}

The anti-elastase activity of Plectranthus spp. organic extracts (Figure 6(A)) revealed impaired elastase inhibition, in contrast to the previous enzymatic assays regarding tyrosinase and collagenase inhibitory activity. Under the experimental conditions, the maximum elastase inhibition obtained was $42.84 .2 \%$ for $P$. grandidentatus ethyl acetic extract, while the positive control, ursolic acid, inhibited elastase by $69.93 .7 \%$. The organic extracts from $P$. madagascariensis and the acetonic extract from $P$. grandidentatus showed no elastase inhibition ( $p>0.05)$.

Mild elastase inhibition (around 30\%) was observed for the organic extracts from $P$. neochilus and $P$. ecklonii, probably due to the presence of different types of triterpenes, such as compounds (7), (8), (14) and (15). Moreover, previous studies suggested that polyphenolic compounds may have anti-elastase activity due to interaction of the hydroxyl groups with the elastase domain 20 . Therefore, the Plectranthus spp. aqueous extracts expected to have this type of compounds, were further evaluated for anti-elastase activity (Figure 6(B)).

The results on Figure $6(B)$ reveal that the aqueous extracts from Plectranthus spp. plants were not effective as elastase inhibitors $(p>0.05)$, being the $P$. grandidentatus aqueous extract the only one able to inhibit the elastase enzyme, by $23.810 .0 \%$ $(p<0.0001)$. This result can be attributed to different and decreased synergy of the polyphenols present in $P$. grandidentatus aqueous extract, in comparison with the remaining aqueous extracts $^{34}$. Nevertheless, the isolated compounds from both organic and aqueous extracts were further assessed for their ability to inhibit elastase activity (Figure $6(\mathrm{C})$ ).

In marked contrast to the Plectranthus extracts, the isolated compounds were strong elastase inhibitors. In accordance with the positive control, ursolic acid, compounds (7) and (8) in 4:1 mixture showed a high anti-elastase activity of $63.4 \quad 2.7 \%$ $(p<0.0001)$. These preliminary results strengthen the literature reports regarding the anti-elastase activity of the pentacyclic triterpenes ${ }^{20,36,40-42}$. On the other hand, compounds with pentacyclic triterpene structure similar to that of compound (8), such as (14) and (15), which were anticipated to have high anti-elastase activity according to previous studies ${ }^{40}$, showed no significant activity. This may be due to interaction on elastase possibly involving different subdomains ${ }^{20}$.

Besides the triterpenes, royleanone-like diterpenes were also very effective in elastase inhibition. These compounds, including (4) (52.8 3.8\%), (2) (39.2 5.2\%) and (3) (38.3 4.4\%), showed highest elastase inhibitory activity (Figure $6(C)$ ). Thus, elastase inhibitors obtained from Plectranthus spp. plants are possible candidates for the treatment or prevention of skin photoageing.

The results obtained with the isolated compounds from Plectranthus spp. plants concerning the in vitro enzyme inhibitory assays of the three skin-related enzymes (tyrosinase, collagenase and elastase), which are summarised in Table 2, suggest that Plectranthus spp. natural products are promising bioactive agents for future formulations against hyperpigmentation, wrinkle, and sagging of the skin.

The experimental results showed that the methanolic extracts from $P$. ecklonii and $P$. madagascariensis, as well as the $P$. grandidentatus ethyl acetic extract, generally had the highest values for radical scavenging activity and enzymatic inhibition. Interestingly, the isolated compounds mainly present in these plant extracts (abietane diterpenes, triterpenes, and polyphenols) also revealed high inhibitory effects on tyrosinase, collagenase and elastase enzymes. The highest inhibitory activity of $P$. porcatus aqueous extract in the anti-tyrosinase assay, which contains only minor amounts of polyphenolic compounds, is probably due to the presence of the diterpenoid (9). Despite the lower efficiency observed in the elastase inhibition assay, the abietane diterpene (4) showed high inhibitory activity only surmounted by the triterpene mixture of (7-8).

In summary, all the plants had antioxidant properties, with methanolic extract having the highest scavenging activity compared to other organic extracts. The organic extracts showed promising results. $P$. grandidentatus acetonic extract, $P$. eckolonii methanolic extract and $P$. saccatus acetonic extract showed high tyrosinase inhibition. The aqueous extracts were not good inhibitors, except for $P$. porcatus extract which was better than the other plants extracts. The isolated compounds (1), (3) and (4), from both organic and aqueous extracts, were able to inhibit tyrosinase. The organic extract showed high collagenase inhibition, the highest anti-collagenase activity was observed for $P$. neochilus methanolic extract. For the aqueous extracts, $P$. ecklonii showed the highest inhibition. Compounds (3), (4) and (17) also showed good inhibition.

The organic extracts were not good inhibitors of the elastase enzyme, the percentage inhibition was too low compare to the positive control. $P$. grandidentatus ethyl acetic extract have some activity but it was low. The aqueous extracts were also not good inhibitors of elastase, again $P$. grandidentatus was better than all the other plants extracts but it was not good.

Thus, due to their antioxidant properties and in vitro ability to inhibit the skin-related enzymes (tyrosinase, collagenase, and 
elastase), the Plectranthus spp. extracts and isolated compounds represent promising bioactive agents with strong potential in cosmetic and/or pharmaceutical formulations to be developed against wrinkling, photo-ageing, hyperpigmentation and sagging of the skin. With this objective in mind, an article has recently been published that studies two different basic formulations containing $P$. ecklonii extracts, one in an organic solvent and the other using water ${ }^{56}$.

Recent discoveries on non-neuronal cholinergic system as a regulator of skin (patho)physiology have drawn attention to the importance of acetylcholinesterase (AChE) in the human skin ${ }^{57,58}$. Apart from the extensively known role of $\mathrm{AChE}$ in the termination of nerve impulse transmission at the cholinergic synapses by rapid hydrolysis of the neurotransmitter acethylcholine, the rationale underlying the use of AChE inhibitors in the symptomatic treatment of Alzheimer's disease ${ }^{59,60}$. Thus, further studies concerning anti-AChE activity in vitro will be conducted based on previous reports of high AChE inhibition by some Plectrathus spp. aqueous extracts $(P$. ecklonii, $P$. grandidentatus, $P$. ornatus, $P$. porcatus and $P$. saccatus) attributed to the presence of rosmarinic (17) and caffeic acids as major compounds ${ }^{14,34,44,61,62}$.

\section{Disclosure statement}

The authors declare no competing financial interests.

\section{Funding}

This work was supported in part by FCT - Fundação para a Ciência e Tecnologia grants PEst-OE/SAU/UI4013/2014, UID/DTP/04567/ 2016, UIDB/04567/2020 and UIDP/04567/2020. E.M.D-M gratefully acknowledges being the recipient of a predoctoral FPU 2019 fellowship from the University of Alcalá.

\section{ORCID}

Joana M. Andrade iD http://orcid.org/0000-0002-2088-4451 Eva María Domínguez-Martín (iD) http://orcid.org/0000-00027884-4292

Marisa Nicolai iD http://orcid.org/0000-0002-2490-2522

Célia Faustino (D) http://orcid.org/0000-0002-4599-8404

Luís Monteiro Rodrigues (D http://orcid.org/0000-0003-0198-7671

Patrícia Rijo (ID) http://orcid.org/0000-0001-7992-8343

\section{References}

1. Neill US. Skin care in the aging female: myths and truths. J Clin Invest 2012;122:473-7.

2. Shamim-Uzzaman QA, Pfenninger D, Kehrer C, et al. Altered cutaneous microvascular responses to reactive hyperaemia in coronary artery disease: a comparative study with conduit vessel responses. Clin Sci (Lond) 2002;103:267-73.

3. Rizzoni D, Porteri E, Boari GE, et al. Prognostic significance of small-artery structure in hypertension. Circulation 2003; 108:2230-5.

4. Cui J, Arbab-Zadeh A, Prasad A, et al. Effects of heat stress on thermoregulatory responses in congestive heart failure patients. Circulation 2005;112:2286-92.

5. Khan F, Litchfield SJ, Stonebridge PA, Belch JJ. Lipid-lowering and skin vascular responses in patients with hypercholesterolaemia and peripheral arterial obstructive disease. Vasc Med 1999;4:233-8.

6. Stewart J, Kohen A, Brouder D, et al. Noninvasive interrogation of microvasculature for signs of endothelial dysfunction in patients with chronic renal failure. Am J Physiol Heart Circ Physiol 2004;287:H2687-96.

7. Tavares L, Palma L, Santos O, et al. Impact of overweight on the normal physiology of human in vivo skin. Biomed Biopharm Res 2013;10:55-63.

8. Rodrigues LM, Palma L, Santos O, et al. Excessive weight favours skin physiology - Up to a point: Another expression of the obesity paradox. Skin Pharmacol Physiol 2017;30: 94-101.

9. Blaak J, Lüttje D, John SM, Schürer NY. Irritability of the skin barrier: a comparison of chronologically aged and photoaged skin in elderly and young adults. Eur Geriatr Med 2011;2:208-11.

10. Krueger $\mathrm{N}$, Luebberding $\mathrm{S}$, Oltmer $\mathrm{M}$, et al. Age-related changes in skin mechanical properties: a quantitative evaluation of 120 female subjects. Skin Res Technol 2011;17: 141-8.

11. Egeberg A, Hansen PR, Gislason GH, Thyssen JP. Patients with rosacea have increased risk of dementia. Ann Neurol 2016;79:921-8.

12. Ravn $\mathrm{AH}$, Thyssen JP, Egeberg A. Skin disorders in Parkinson's disease: potential biomarkers and risk factors. Clin Cosmet Investig Dermatol 2017;10:87-92.

13. Vallisuta O, Nukoolkarn V, Mitrevej $A$, et al. In vitro studies on the cytotoxicity, and elastase and tyrosinase inhibitory activities of marigold (Tagetes erecta L.) flower extracts. Exp Ther Med 2014;7:246-50.

14. Ghimeray AK, Jung US, Lee HY, et al. In vitro antioxidant, collagenase inhibition, and in vivo anti-wrinkle effects of combined formulation containing Punica granatum, Ginkgo biloba, Ficus carica, and Morus alba fruits extract. Clin Cosmet Investig Dermatol 2015;8:389-96.

15. Moon JY, Yim EY, Gwanpil S, et al. Screening of elastase and tyrosinase inhibitory activity from Jeju Island plants. Eurasian J Biosci 2010;4:41-53.

16. Thring TS, Hili P, Naughton DP. Antioxidant and potential anti-inflammatory activity of extracts and formulations of white tea, rose, and witch hazel on primary human dermal fibroblast cells. J Inflamm 2011;8:27.

17. Abdul Wahab N, Abdul RR, Ismail A, et al. Assessment of antioxidant capacity, anti-collagenase and anti-elastase assays of Malaysian unfermented cocoa bean for cosmetic application. Nat Prod Chem Res 2014;2:1000132.

18. Ray PD, Huang BW, Tsuji Y. Reactive oxygen species (ROS) homeostasis and redox regulation in cellular signaling. Cell Signal 2012;24:981-90.

19. Jung HY, Shin JC, Park SM, et al. Pinus densiflora extract protects human skin fibroblasts against UVB-induced photoaging by inhibiting the expression of MMPs and increasing type I procollagen expression. Toxicol Rep 2014;1:658-66.

20. Lee KK, Cho JJ, Park EJ, Choi JD. Anti-elastase and anti-hyaluronidase of phenolic substance from Areca catechu as a new anti-ageing agent. Int J Cosmet Sci 2001;23:341-6.

21. Chen WC, Tseng TS, Hsiao NW, et al. Discovery of highly potent tyrosinase inhibitor, T1, with significant anti-melanogenesis ability by zebrafish in vivo assay and computational molecular modeling. Sci Rep 2015;5:7995

22. Rijo $P$, Falé $P L$, Serralheiro $M L$, et al. Optimization of medicinal plant extraction methods and their encapsulation 
through extrusion technology. Measurement 2014;58: 249-55.

23. Rosa S, Correia V, Ribeiro I, et al. In vitro antioxidant properties of the diterpenes Parvifloron $D$ and $7 \alpha$-acetoxy- $6 \beta$ hydroxyroyleanone. Biomed Biopharm Res 2015;12:59-67.

24. Ascensão L, Figueiredo AC, Barroso JG, et al. Plectranthus madagascariensis: morphology of the glandular trichomes, essential oil composition, and its biological activity. Int J Plant Sci 1998;159:31-8.

25. Abdel-Mogib M, Albar HA, Batterjee SM. Chemistry of the genus Plectranthus. Molecules 2002;7:271-301.

26. Rice LJ, Brits GJ, Potgieter CJ, Van Staden J. Plectranthus: a plant for the future? South African J Bot 2011;77:947-59.

27. Lukhoba CW, Simmonds MS, Paton AJ. Plectranthus: a review of ethnobotanical uses. J Ethnopharmacol 2006;103:1-24.

28. Rijo P, Faustino $C$, Simões MF, Antimicrobial natural products from Plectranthus plants. In: Méndez-Vilas A, ed. Microbial pathogens and strategies to combating them: science, technology and education 2. Badajoz, Spain: Formatex; 2013.

29. Naghibi F, Mosaddegh M, Motamed SM, Ghorbani A. Labiatae family in folk medicine in Iran: from ethnobotany to pharmacology. Iran J Pharm Res 2005;2:63-79.

30. Rijo P, Simões MF, Rodriguez B. Structural and spectral assignment of three forskolin-like diterpenoids isolated from Plectranthus ornatus. Magn Reson Chem 2005;43:595-8.

31. Simões MF, Rijo P, Duarte A, et al. An easy and stereoselective rearrangement of an abietane diterpenoid into a bioactive microstegiol derivative. Phytochem Lett 2010;3:234-7.

32. Simões MF, Rijo $P$, Duarte $A$, et al. Two new diterpenoids from Plectranthus species. Phytochemistry Letters 2010;3: 221-5.

33. Rijo $P$, Batista $M$, Matos $M$, et al. Screening of antioxidant and antimicrobial activities on Plectranthus spp. extracts. Biomed Biopharm Res 2012;9:225-35.

34. Rijo $\mathrm{P}$, Duarte $\mathrm{A}$, Francisco $\mathrm{AP}$, et al. In vitro antimicrobial activity of royleanone derivatives against Gram-positive bacterial pathogens. Phytother Res 2014;28:76-81.

35. Pandey KB, Rizvi SI. Plant polyphenols as dietary antioxidants in human health and disease. Oxid Med Cell Longev 2009;2:270-8.

36. Tu PT, Tawata S. Anti-oxidant, anti-aging, and anti-melanogenic properties of the essential oils from two varieties of Alpinia zerumbet. Molecules 2015;20:16723-40.

37. Masuda M, Murata K, Fukuhama A, et al. Inhibitory effects of constituents of Morinda citrifolia seeds on elastase and tyrosinase. J Nat Med 2009;63:267-73.

38. Popoola OK, Marnewick JL, Rautenbach F, et al. Inhibition of oxidative stress and skin aging-related enzymes by prenylated chalcones and other flavonoids from Helichrysum teretifolium. Molecules 2015;20:7143-55.

39. Nsimba RY, Kikuzaki H, Konishi Y. Ecdysteroids act as inhibitors of calf skin collagenase and oxidative stress. J Biochem Mol Toxicol 2008;22:240-50.

40. Thring TS, Hili P, Naughton DP. Anti-collagenase, anti-elastase and anti-oxidant activities of extracts from 21 plants. BMC Complement Altern Med 2009;9:27.

41. Barrantes $E$, Guinea M. Inhibition of collagenase and metalloproteinases by aloins and aloe gel. Life Sci 2003;72: 843-50.

42. Baylac S, Racine P. Inhibition of human leukocyte elastase by natural fragrant extracts of aromatic plants. Int J Aromather 2004;14:179-82.
43. Ying QL, Rinehart AR, Simon SR, Cheronis JC. Inhibition of human leucocyte elastase by ursolic acid. Evidence for a binding site for pentacyclic triterpenes. Biochem J 1991;277: 521-6.

44. Pereira M, Matias D, Pereira F, et al. Antimicrobial screening of Plectranthus madagascariensis and $P$. neochilus extracts. Biomed Biopharm Res 2015;12:127-38.

45. Rijo P, Gaspar-Marques C, Simões MF, et al. Further diterpenoids from Plectranthus ornatus and $P$. grandidentatus. Biochem Syst Ecol 2007;35:215-21.

46. Rijo P, Simões MF, Francisco AP, et al. Antimycobacterial metabolites from Plectranthus: Royleanone derivatives against Mycobacterium tuberculosis strains. Chem Biodivers 2010;7:922-32.

47. Rijo P, Gaspar-Marques C, Simões MF, et al. Neoclerodane and labdane diterpenoids from Plectranthus ornatus. J Nat Prod 2002;65:1387-90.

48. Martins IL, Miranda JP, Oliveira NG, et al. Synthesis and biological activity of 6-selenocaffeine: potential modulator of chemotherapeutic drugs in breast cancer cells. Molecules 2013;18:5251-64.

49. Yamauchi K, Mitsunaga T, Batubara I. Isolation, identification and tyrosinase inhibitory activities of the extractives from Allamanda cathartica. Nat Resour 2011;02:167-72.

50. Van Wart HE, Steinbrink DR. A continuous spectrophotometric assay for Clostridium histolyticum collagenase. Anal Biochem 1981;113:356-65.

51. Wittenauer J, Mäckle S, Sußmann D, et al. Inhibitory effects of polyphenols from grape pomace extract on collagenase and elastase activity. Fitoterapia 2015;101:179-87.

52. Bieth J, Spiess B, Wermuth CG. The synthesis and analytical use of a highly sensitive and convenient substrate of elastase. Biochem Med 1974;11:350-7.

53. Do QD, Angkawijaya $A E$, Tran-Nguyen $\mathrm{PL}$, et al. Effect of extraction solvent on total phenol content, total flavonoid content, and antioxidant activity of Limnophila aromatica. J Food Drug Anal 2014;22:296-302.

54. Riley PA. Melanin. Int J Biochem Cell Biol 1997;29:1235-9.

55. Shadyro OI, Glushonok GK, Glushonok TG, et al. Quinones as free-radical fragmentation inhibitors in biologically important molecules. Free Radic Res 2002;36:859-67.

56. Nicolai M, Mota J, Fernandes AS, et al. Assessment of the Potential Skin Application of Plectranthus ecklonii Benth. Pharmaceuticals 2020;13:120-10.

57. Schiller E, Free radicals and inhalation pathology. BerlinHeidelberg, Germany: Springer-Verlag; 2004.

58. Kurzen H, Wessler I, Kirkpatrick CJ, et al. The non-neuronal cholinergic system of human skin. Horm Metab Res 2007;39: 125-35.

59. Tabet N. Acetylcholinesterase inhibitors for Alzheimer's disease: anti-inflammatories in acetylcholine clothing!. Age Ageing 2006;35:336-8.

60. Boora F, Chirisa E, Mukanganyama S. Evaluation of nitrite radical scavenging properties of selected Zimbabwean plant extracts and their phytoconstituents. J Food Process 2014; 2014:1-7.

61. Falé $\mathrm{PL}$, Madeira $\mathrm{PJ}$, Florencio $\mathrm{MH}$, et al. Function of Plectranthus barbatus herbal tea as neuronal acetylcholinesterase inhibitor. Food Funct 2011;2:130-6.

62. Kubínová R, Pořizková R, Navrátilová $A$, et al. Antimicrobial and enzyme inhibitory activities of the constituents of Plectranthus madagascariensis (Pers.) Benth. J Enzyme Inhib Med Chem 2014;29:749-52. 